\title{
Modelos del proceso de redacción: algunas implicaciones para la enseñanza
}

\author{
ANNA CAMPS \\ Universidad Autónoma de Barcelona

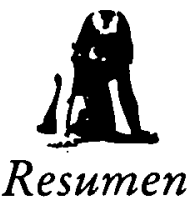

Los modelos cognitivos del proceso de redacción muestran la complejidad de dichos procesos y la dificultad del dominio de todos los conocimientos y babilidades que requieren. De su análisis se desprende que los subprocesos y operaciones que se llevan a cabo durante la redacción no son lineales, sino recursivos. Por otra parte, muestran que escribir no consiste sólo en plasmar por escrito lo que se piensa, sino que la escritura puede tener una función epistémica, puede contribuir a la elaboración del pensamiento.

Las consecuencias para la enseñanza se resumen en la necesidad de intervención del maestro durante el proceso de escritura, en la conveniencia de enfocar selectivamente la enseñanza de los conocimientos, habilidades y estrategias necesarios sin perder de vista la actividad global $y$ en la necesidad de enseñar unos procesos adecuados para que la escritura pueda llegar a ser instrumento de conocimiento.

Palabras clave: Modelos del proceso de redacción, Enseñanza de la redacción, Estrategias cognitivas, Elaboración de los conocimientos, Sobrecarga cognitiva.

\section{Writing process models: some implications for language instruction.}

\section{Abstract}

Cognitive models of writing processes reveal the complexity of such processes and the difficulty of mastering the knowledge and skills they require. From their analyses it has been established that the subprocesses and operations which take place during composition are not linear but recursive. Moreover, writing is not simply the act of putting in writing what one thinks, it seems to have an epistemic function, contributing to the elaboration of thought.

The consequences for intruction are summarized as follows: the necessity of teacher intervention during writing, the convenience of adopting a selective approach in teaching the necessary knowledge, skills, and strategies, without loosing sight of the activity as a whole. Also, it is necessary that adequate processes are taught so that writing may become a tool of knowledge.

Keywords: Writing process models, Writing instruction, Cognitive strategies, Elaboration of Knowledge, Cognitive overload.

Dirección del autor: Sección de Filología, Escuela de Formación de Profesorado «Sant Cugatm. Universidad Autónoma de Barcelona. 08193 Bellaterra. Barcelona.

Original recibido: Noviembre 1989. Revisión recibida: Noviembre 1989. Aceptado: Diciembre 1989. 
El análisis de los procesos redaccionales tiene ya una tradición de más de 10 años y las implicaciones para la enseñanza son numerosas. Desde los primeros intentos de derivar modelos didácticos a partir de los modelos de los procesos cognitivos en adultos, a los estudios más recientes centrados en el análisis y la interacción de la multiplicidad de factores que inciden tanto en el desarrollo de la capacidad de redacción como en la elaboración de modelos didácticos que den soporte a las actividades de enseñanza/aprendizaje, las investigaciones se han multiplicado y han puesto de manifiesto la necesidad de renovar en las escuelas las prácticas de enseñanza de la redacción, una de las habilidades básicas que tradicionalmente tiene asignada.

Este artículo no pretende agotar el tema. La intención es mostrar las aportaciones de algunos modelos cognitivos que parecen especialmente significativas por la incidencia que tienen en el análisis de las propuestas didácticas de la redacción.

\section{LOS MODELOS DE ETAPAS}

Los primeros estudios sobre la redacción que no se centraron exclusivamente en el análisis del texto como producto estaban orientados a probar la eficacia de métodos pedagógicos para mejorar la cualidad de los escritos de los alumnos. Uno de los que más influencia ha tenido en el campo de la enseñanza ha sido el de Rohman y Wlecke (1964), que estableció tres etapas en el proceso de escritura: pre-escritura, etapa de descubrimiento de ideas, de «invención»; escritura, en que tiene lugar la producción real del escrito; y re-escritura en la cual se reelabora el primer producto para obtener el escrito final. Las tres etapas que este modelo describe son discretas y sucesivas. Se presupone que, si se siguen de forma ordenada, el escritor puede llegar a obtener un escrito aceptable.

Los modelos de etạpas han tenido una gran aceptación en la enseñanza, de donde surgieron, porque ofrecen a los enseñantes la posibilidad de incidir de manera ordenada y estrictamente programada en el proceso de producción considerado lineal y unidireccionalmente. La tarea del maestro consistiría en instruir al niño en las técnicas adecuadas que corresponden a las características de las tareas propias de cada etapa: cómo generar ideas, cómo combinar frases, seleccionar palabras, etc., cómo revisar el texto producido, etc. La aplicación de estos modelos presupone que la instrucción en unas determinadas técnicas contribuirá a la mejora de la capacidad de redactar. Con esta orientación se han elaborado diversos modelos pedagógicos de tipo prescriptivo que especifican los pasos que hay que seguir para producir un texto aceptable. Por la facilidad de aplicación, han sido adoptados por numerosos autores de libros de texto.

Desde el punto de vista de la investigación, esos modelos tuvieron importancia porque atrajeron la atención de los investigadores hacia el proceso de elaboración del escrito y no sólo hacia el producto. De todas formas presentan dos grandes problemas que exigen revisar su aplicación ingenua a la enseñanza. En primer lugar, las investigaciones posteriores han demostrado que el proceso de composición del texto no es lineal: el escritor hace y rehace constantemente, planifica y replanifica sobre la marcha, reescribe, corrige, etc. Parece, pues, que no sigue una serie de etapas discretas, sino una serie de subprocesos que interactúan unos con otros. En 
segundo lugar, el modelo de etapas se centra en el proceso de crecimiento del texto, del producto, sin tener en cuenta los procesos internos del escritor.

\section{LOS MODELOS COGNITIVOS}

Los modelos cognitivos intentan explicar cuáles son los procesos que el escritor sigue durante la tarea de escritura. La atención, en estos modelos, se centra en las estrategias y conocimientos que el escritor pone en funcionamiento para escribir y en la forma como interactúan durante el proceso. Los subprocesos se ven, no como etapas que hay que seguir una detrás de otra, sino como operaciones que hay que realizar y que a menudo se aplican recursivamente. En el año 1964, Emig lanzó un ataque frontal al modelo de Rohman y Wlecke en una conferencia que no fue publicada hasta el año 1971. Emig concluye que la planificación tiene lugar durante todo el proceso de redacción y no está claramente separada del proceso de ejecución.

La investigación de Emig fue pionera de una serie de estudios orientados a examinar las estrategias de redacción, que se llevaron a cabo con metodologías diversas. Los investigadores infirieron estrategias de los análisis de protocolos de "pensamiento oralizado» (la misma Emig, 1971; Flower y Hayes, 1980), del análisis del comportamiento durante la escritura (Matsuhashi, 1982), del análisis de textos (Bridwell, 1980; Perera, 1984), entre otros. La pretensión de estas investigaciones es construir un modelo abstracto que sirva de hipótesis del proceso, de las operaciones que se llevan a cabo y de los factores que influyen en él, tanto los contextuales como los que se refieren a las características cognitivas y a los conocimientos del escritor.

La serie de estudios de Flower y Hayes (1980, 1981; Hayes y Flower, 1980) contribuyeron a establecer el estudio de las estrategias de redacción como una importante línea de investigación y le dieron unos fundamentos teóricos. Enfocaron sus investigaciones al acto de escritura, es decir al proceso de escritura y no al producto, y utilizaron la técnica de hacer pensar en voz alta a los escritores mientras realizaban la tarea que les habian asignado. Después analizaron los protocolos obtenidos de las grabaciones.

Estos autores consideran el modelo que presentan como una metáfora de lo que realmente sucede cuando un escritor produce un texto; porque, como afirman, no todos los escritores escriben igual y su objetivo es explicar la conducta de los escritores individuales.

El modelo de Hayes y Flower (ver Figura 1) está formado por tres partes o componentes, entre las cuales se establecen diversas interrelaciones: la memoria a largo plazo del escritor, el contexto de producción, que consta de los elementos que configuran la situación retórica y del texto producido en cada momento y, finalmente, el proceso propiamente dicho.

La memoria a largo plazo incluye todos los conocimientos del escritor sobre contenidos temáticos, sobre imágenes de receptores posibles y sobre esquemas textuales.

El contexto de producción se refiere a la situación concreta en la que se produce el escrito. La tarea de redacción presenta una serie de problemas retóricos, que el escritor tendrá que resolver, relacionados con la intención del escrito, con el receptor o receptores a los que se dirige y con el tema 
FIGURA 1

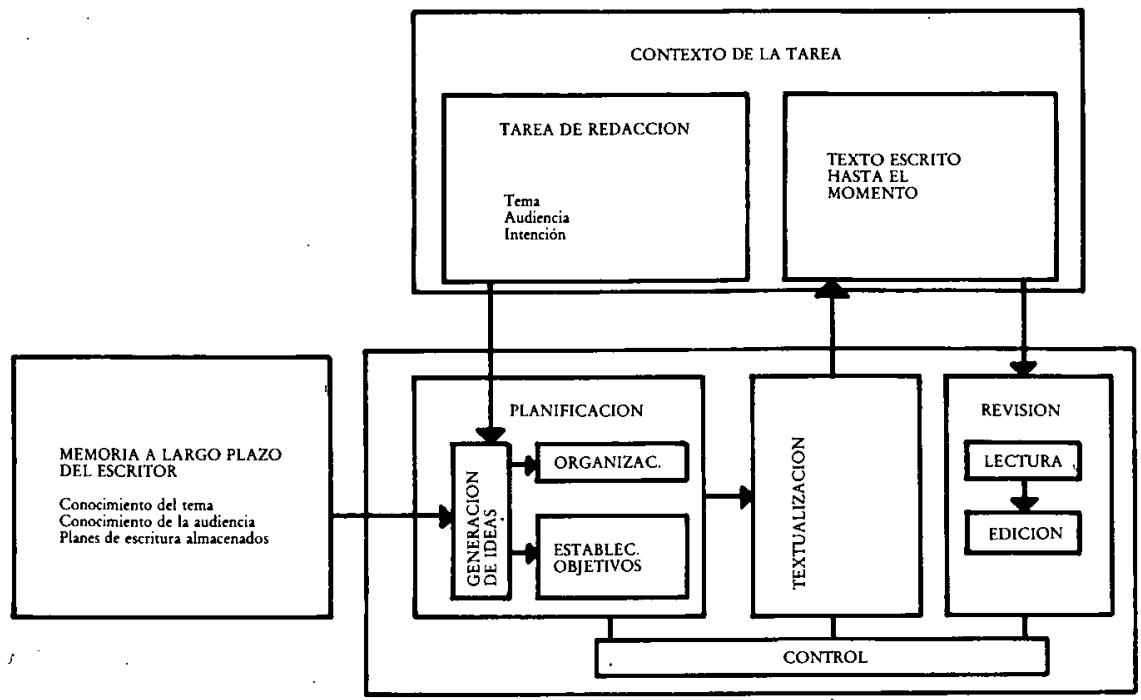

Estructura del modelo de escritura (Hayes y Flower 1980, p. 11).

concreto de que trata. A medida que se escribe, el texto ya producido genera una serie de exigencias y limitaciones, es un elemento más del contexto.

Las principales operaciones que configuran el proceso propiamente son:

\section{La planificación}

Que consiste en definir los objetivos del texto y establecer el plan que guiará el conjunto de la producción. Esta operación consta, a su vez, de tres subprocesos: la concepción o generación de ideas, la organización $y$, finalmente, el establecimiento de objetivos en función de la situación retórica. Los autores distinguen dos tipos de planes: los procesuales, que tratan de la forma en que los escritores realizarán el proceso, y los de contenido, la función de los cuales es transformar las ideas en texto escrito.

\section{La textualización}

Está constituida por el conjunto de operaciones de transformación de los contenidos en lenguaje escrito linealmente organizado. La multiplicidad de demandas de esta operación (ejecución gráfica de las letras, exigencias ortográficas, léxicas. morfológicas, sintácticas, etc.), que consiste en pasar de una organización semántica jerarquizada a una organización lineal, obliga a frecuentes revisiones y retornos a operaciones de planificación.

\section{La revisión.}

Que consiste en la lectura y posterior corrrección y mejora del texto. Durante la lectura, el escritor evalúa el resultado de la escritura en función de los objetivos del escrito y evalúa también la coherencia del contenido en función de la situación retórica. 
Este proceso parece coincidir en sus componentes con el de Rohman y Wlecke, pero hay una diferencia fundamental entre ambos: la noción de "monitor", de control, que Flower y Hayes toman del campo de la cibernética. Este mecanismo tiene como función controlar, dirigir, la secuencia del proceso de redacción; permite tomar decisiones, como por ejemplo, en qué momento se puede dar por terminado un subproceso, en qué momento es necesaria una revisión parcial porque se percibe un desajuste, si es necesario o no reformular los objetivos, etc. Exige por tanto del escritor una determinada capacidad metacognitiva.

Flower y Hayes consideran que la redacción empieza cuando se presenta al escritor una situación retórica como por ejemplo una tarea escolar de redacción. A partir de la representación del problema, el escritor crea una red jerarquizada de objetivos que, de todas formas, podrán ser modificados en el decurso de la redacción porque el proceso, como apuntábamos, no es lineal sino recursivo, en el sentido de que en cualquier momento se puede aplicar de nuevo el proceso para resolver un error, añadir algo que falta, etc. El análisis de las operaciones que llevan a cabo los escritores expertos (a través del análisis de los protocolos de pensamiento oral) demuestran que éstos efectúan constantes idas y venidas entre los diferentes niveles de organización y escritura del texto.

Los autores, aunque reconocen que los procesos «top down» y «bottom up» tienen que considerarse complementarios, creen que las operaciones tinen lugar por un proceso preferentemente descendente. El escritor toma en primer lugar información del contexto y de la memoria a largo plazo para establecer los objetivos que dirigirán la producción del texto. Las decisiones a nivel más bajo están subordinadas a los objetivos de nivel más alto.

A pesar de la insistencia en la idea de recursividad, en el modelo de Hayes y Flower parece aún implícita una cierta concepción de secuenciación lineal del proceso, aunque la aplicación sea distinta de un escritor a otro. La recursividad parece reducida a la aplicación, cuantas veces sea necesario, de los sub-procesos de planificación y textualización después de operaciones de revisión.

De Beaugrande $(1982,1984)$, a partir de la experiencias de simulación sobre la comprensión del discurso, desarrolló lo que llamó modelo de interacción de estadios paralelos ("parallelstage interaction models»). Según este autor la producción del texto es una actividad compleja que interactúa con una gran diversidad de circunstancias físicas, psicológicas y sociales. Por este motivo considera inadecuados los modelos de la teoría de la información que describen la comunicación como el proceso de codificación/descodificación del mensaje que un emisor envía a un receptor, y que conciben el código como un conjunto fijo de símbolos no ambiguos y definidos arbitrariamente. Un modelo de este tipo no hace referencia a motivaciones, decisiones y contextos de la comunicación real.

Según De Beaugrande la complejidad de la producción textual no permite formular un modelo rígido, sino que sería necesario incorporar a él múltiples causas potenciales y estipular las posibles interacciones entre ellas. La relativa probabilidad de dichas causas indicaría de forma más adecuada la relación entre los modelos del proceso y las actividades reales de producción. 
Establece algunos criterios que deberían presidir la formulación de modelos de producción. Destacaremos los siguientes:

- El proceso de producción no es inverso al de recepción sino que uno y otro abordan el texto desde perspectivas fundamentalmente diferentes. Por ejemplo, el receptor puede tratar los materiales de manera provisional o incompleta, en cambio el productor debe continuar la tarea hasta que el texto ha sido producido.

- Un modelo ha de ser flexible, ha de poder dar cuenta de la variación entre individuos con diferentes habilidades y estilos. Ello no significa que el modelo no tenga que ser sistemático.

- El procesador puede operar a diferentes niveles de profundidad. Los niveles más profundos (jerarquización de ideas, objetivos, etc.) tienen un efecto mayor en la memoria y en la producción. El resultado puede variar según sean los niveles de profundidad en los que se ha operado.

- Los recursos de que dispone el procesador son casi siempre limitados; por tanto, a menudo se da un desajuste entre los distintos requerimientos de la tarea en curso. Cuando la demanda es demasiado grande el sistema en su totalidad manifiesta una sobrecarga que requiere compensación. Si los recursos no aumentan, las operaciones se degradan. Parece que la producción textual opera cerca del límite de sobrecarga.

- Son los procesos conscientes los que entran en conflicto con otras operaciones en un momento determinado, en tanto que los automáticos pueden seguir su curso. De todas formas, estos últimos pueden causar problemas si hay que introducir algún cambio en ellos. La producción experta relaciona estratégicamente procesos automáticos y no automáticos.

- El proceso es interactivo, es decir, sus componentes son cooperantes entre sí. Los estadios de desarrollo del proceso son paralelos, las diversas operaciones funcionan en concurrencia o tienen en cuenta los resultados de las otras. El procesador designa en qué orden se llevarán a cabo las operaciones que pueden ser rutinarias, usuales, o específicas, adaptadas a requerimientos especiales de la tarea.

- El proceso de escritura es abierto, es decir no tiene un punto fijo de finalización. El texto puede ser siempre reconsiderado. Es el escritor quien establece el umbral en que se da por satisfecho. La revisión es una reconsideración de dicho umbral.

- La memoria relaciona conocimiento y realización durante el proceso. Es constructiva, suministra activamente los conocimientos y es reconstructiva, es decir que los conocimientos continúan evolucionando a lo largo la tarea.

- Durante el proceso, se da aprendizaje cuando el procesador tiene que adaptarse en el curso de una operación o de una serie de operaciones. $\mathrm{La}$ educación en la escritura depende de que las tareas motiven un constante refinamiento de los modelos lingüísticos de los aprendices. Las actividades de corrección, por ejemplo, sólo serán una ayuda si los alumnos pueden relacionar las decisiones de nivel superficial con las ideas y objetivos de nivel profundo.

- La tipología de los textos sobre los cuales se puede operar puede basarse en procesos y contextos y no sólo en las características del producto. 
En un modelo paralelo e interactivo los distintos niveles de lenguaje son procesados en fases concurrentes definidas por las operaciones que se llevan a término. No hay que considerarlas pues como fases que se desarrollan temporalmente sino como unidades funcionales. El escritor asigna la dominancia de un estadio hasta que se da por satisfecho con el nivel conseguido, momento en que se impondrá el cambio a otra dominancia, que no tiene que ser necesariamente la inmediatamente adyacente; al contrario, se puede cambiar a un estadio anterior y volver a empezar las operaciones o revisar las decisiones tomadas. En la Figura 2 la línea negra que recorre

FIGURA 2

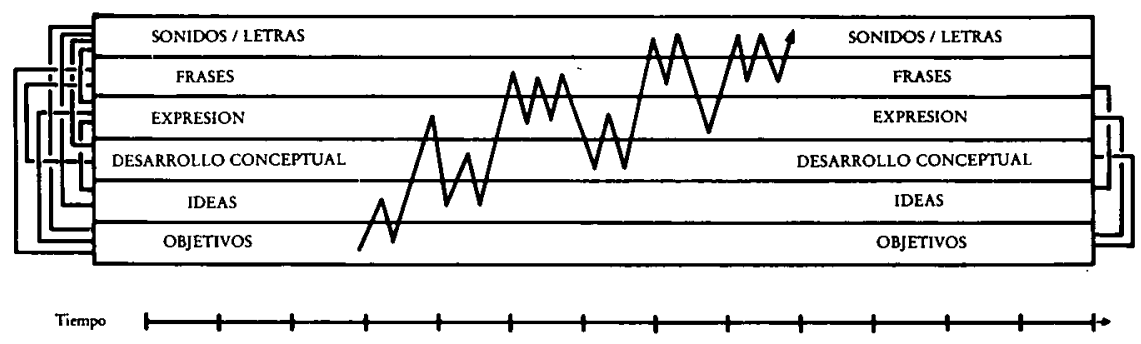

Modelo de estadios paralelos (R. de Beaugrande 1984, p. 106).

en zig-zag las operaciones indica un posible paso de una dominancia a otra durante el proceso de redacción. Cada operación es, pues, dominante en cada punto y, por tanto, controla la atención del escritor.

Los estadios son:

1. Establecimiento de objetivos generales del texto y de los sub-objetivos que se quieren conseguir a lo largo del proceso.

2. Ideación, que tiene lugar en los momentos iniciales de la configuración global y en la cual se establece, por ejemplo, el tema principal.

3. Desarrollo conceptual, que comprende la elaboración, especificación e interconexión de ideas.

4. Expresión, que consiste en adaptar los conceptos a la expresión lingüística mediante la selección de palabras.

5. La alineación de frases organiza las palabras en grupos de tal forma que la producción lineal se puede llevar a cabo.

6. La actualización en forma de símbolos es llevada a cabo por un ejecutor durante la fase de alineación de sonidos o letras.

En algunos aspectos este modelo es comparable al de Hayes y Flower, pero éste sugiere que la dominancia se cambia por bloques enteros de texto, mientras que el de De Beaugrande asume que, en condiciones normales, los estadios avanzan juntos en cada momento del desarrollo del texto.

En el modelo de De Beaugrande encontramos planteadas algunas cuestiones que creemos cruciales para la enseñanza de la redacción. Podemos destacar: 1) El concepto de aprendizaje asociado al proceso de escritura y la necesidad implícita de que la tarea exija adaptaciones para que el aprendizaje se dé, unido al concepto de memoria reconstructiva, que elabora activamente el conocimiento durante el proceso, constituye un marco en el 
cual basar un posible modelo de enseñanza de la redacción; 2) La situación de sobrecarga puede tener como consecuencia la degradación del proceso, con lo cual el aprendizaje no se daría. De ello podría desprenderse que escribir no siempre es fuente de aprendizaje; que será necesario dominar estrategias adecuadas para resolver el problema.

\section{REDACCION Y ELABORACION DE LOS CONOCIMIENTOS}

Muchos autores destacan que la redacción es un instrumento de elaboración de conocimientos. Las características de permanencia del lenguaje escrito y la posibilidad de reelaboración que permite a través de los posibles borradores sucesivos, parecen idóneas para la función epistémica del lenguaje. Como afirma Wells (1986), la escritura ha transformado la relación de los individuos y de la colectividad alfabetizada con el conocimiento.

En este enfoque podemos considerar dos aspectos. Por un lado parece claro que una sociedad alfabetizada ha integrado la escritura como sistema de relación con el mundo diferente del que implica el uso exclusivo del lenguaje oral. Muchos conocimientos serían imposibles sin la existencia de la escritura. Por otro lado, podemos considerar esta cuestión desde el punto de vista individual del que produce el escrito. Escribir puede incidir en la transformación de los conocimientos individuales. Según esto, redactar no sería sólo expresar los conocimientos que se tienen, sino que a través de esta actividad el escritor establecería nuevas relaciones, profundizaría en el conocimiento, es decir, lo transformaría y aprendería (Bereiter y Scardamalia, 1983; Hayes y Flower, 1981).

En el lenguaje oral la situación de diálogo entre un emisor y un receptor permite la elaboración del conocimiento. Entre los dos interlocutores construyen, elaboran y hacen evolucionar el contenido. El resultado es que ambos, al final de la conversación, no han dicho sólo lo que previamente sabían, sino que sus conocimientos, sus pensamientos, han cambiado gracias a las aportaciones del interlocutor y no sólo en el sentido de haber acumulado nueva información, nuevos conocimientos, sino que de las contradicciones, de los puntos de vista contrapuestos o diferentes han surgido nuevas relaciones, nuevos puntos de vista que han hecho cambiar y evolucionar los pensamientos y las creencias de ambos interlocutores. El problema planteado es cómo se puede dar la elaboración del conocimiento durante la redacción. Para algunos autores esta función es inherente al hecho dè escribir (Hayes y Flower, 1981; Emig, 1971; Wells, 1986). De Beaugrande (1984) atribuye la creatividad en el proceso de ideación, a la posibilidad que tiene el productor del texto de combinar elementos pertenecientes a diferentes esquemas de conocimiento para llegar a producir una nueva idea. Otros autores explican esta función de la escritura estableciendo un paralelismo con el lenguaje oral y dando una importancia fundamental a la imagen del receptor. Según Matsuhashi (1983), en la escritura se daría una especie de diálogo interiorizado en el que el escritor adoptaría la función de emisor y de receptor alternativamente. Widdowson en sus investigaciones sobre el aprendizaje de la redacción en una segunda lengua, considera el discurso escrito como un proceso interactivo de negociación para la cual es necesario que el estudiante sepa a quién se dirige y para qué. 
Según Scardamalia y Bereiter (1985), este punto de vista no tiene base y afirman que la elaboración del conocimiento en la conversación y en la escritura son diferentes. "A pesar del poder generador de la conversación los resultados son productos sociales, negociados con los otros. No poseemos verdaderamente nuestros pensamientos o experiencias hasta que los hemos negociado con nosotros mismos, y para ello, escribir es el medio privilegiado.» Opinan e intentan demostrar que el carácter dialéctico de la escritura proviene del conflicto entre las exigencias del texto y las del pensamiento, es decir, entre lo que se ha llamado "el espacio sustantivo", constituido por las creencias y conocimientos del escritor, y uel espacio retórico» en que se manifiestan los problemas de la redacción en sí misma. El problema dialéctico surge cuando hay interrelación entre ambos espacios.

Parece, sin embargo, que muchas personas cuando escriben no adoptan las estrategias adecuadas para que esto sea posible. De Beaugrande (1984) cita diversos autores que se refieren a las condiciones atípicas, pero frecuentes, de la redacción escolar. Su opinión es que, en general, los estudiantes no adoptan un punto de vista personal sobre un tema y, por tanto, no realizan una verdadera tarea de elaboración del pensamiento porque, además, creen que sus puntos de vista no son relevantes para un trabajo académico. Applebee (1982) observa que, a menudo, los escritos escolares no son más que una exposición de materiales no seleccionados por el escritor. Afirma: «Hemos encontrado muchos ejemplos de trabajos que no eran gran cosa más que un catálogo de "hechos importantes" relacionados unos con otros principalmente desde el punto de vista del profesor». Así pues, según De Beaugrande (1984) la situación escolar impide que los estudiantes desarrollen la habilidad de exponer sus pensamientos por escrito.

Bereiter y Scardamalia (1987) afirman que la función epistémica no es inherente al hecho de escribir. Según estos autores escribir es a la vez natural y problemático. En el primer caso, consiste en un proceso de decir los conocimientos ("knowledge telling"), en el segundo, en un proceso de transformación de los conocimientos ("knowledge transforming"). La diferencia entre uno y otro no radica en el texto escrito, sino en los procesos mentales por los cuales se produce el texto. La diferencia se manifiesta principalmente en las estrategias de generación de ideas, que estos autores no sitúan sólo en la fase anterior al inicio del escrito, sino que consideran implicadas en todo el proceso.

El modelo que Bereiter y Scardamalia (1987) llaman «decir los conocimientos", permite resolver con aparente eficacia los problemas planteados por la redacción. El escritor ha aprendido unas determinadas estrategias que le permiten cumplir con la tarea encomendada de manera aparentemente adecuada. La estrategia predominante que describen es la que consiste en empezar escribiendo una frase general sobre el tema propuesto y, seguidamente, basándose en la última frase escrita, decidir el contenido y la redacción de la siguiente. Otra estrategia propia de este tipo de proceso es la basada en el conocimiento de las superestructuras textuales. La estructura del tipo de texto que se sigue indica el tipo de contenido que hay que desarrollar en cada momento de la redacción. La estructura no estaría en este caso al servicio de los contenidos que se quieren vehicular, sino que, por el contrario, los contenidos servirían a la superestructura. El tema es también un camino para resolver superficialmente los problemas: se producen una de- 
trás de otra, frases que tengan relación con él sin que haya habido un proceso de elaboración de los contenidos ni de la interrelación entre ellos.

Las manifestaciones externas de la adopción de este tipo de proceso son, por un lado, las características de las revisiones parciales durante la escritura que consisten, en general, en leer sólo la última frase escrita para enlazar con ella la siguiente, y, por otro lado, las características de las revisiones generales que se limitan a los aspectos más superficiales del escrito (ortografía, vocabulario, morfología, algunos aspectos sintácticos y poco más) y en que el escritor se muestra incapaz de revisar a niveles más altos.

La hipótesis es que la mayoría de escritos escolares se producen siguiendo un proceso de estas características. El hecho de que los profesores no analicen ni "corrijan" casi nunca los contenidos más que en los aspectos más visibles y no en las interrelaciones entre ellos y que, en la mayoría de los casos, se limiten a corregir los aspectos más superficiales refuerza esta estrategia. Otra causa puede ser que, en muchas ocasiones, especialmente en la clase de lengua, los alumnos escriben sin tener nada que decir, sólo para cumplir la tarea encomendada de "hacer una redacción" sobre un tema dado o de «escribir un texto libre», lo cual muchas veces es escribir sobre cualquier cosa.

En muchos casos la enseñanza de la redacción se orienta precisamente a dotar a los alumnos de recursos para resolver problemas formales: vocabulario, procedimientos para relacionar frases, diferentes maneras de expresar la misma idea, etc. Incluso cuando se introducen aspectos textuales en la enseñanza de la redacción se puede caer en una enseñanza que se limite a las formas, más globales si se quiere y que permiten resolver el problema con más eficacia, pero que, si sólo son recursos formales, pueden no llevar al alumno a utilizar el escrito como medio de transformación del pensamiento.

Escribir no es sólo transcribir unos pensamientos previamente formulados y organizados. No hay necesariamente identidad entre lo que se escribe y lo que se piensa. Para muchas personas escribir es una fuerza organizadora de su desarrollo intelectual y es una tarea de representación de significados más que de transcripción de lenguaje previamente organizado.

Elmodelo que Bereiter y Scardamalia (1987) llaman de «transformación de conocimientos", parece interesante porque atribuye un lugar fundamental a los contenidos (espacio sustantivo) que de forma dialéctica se tienen que relacionar con los conocimientos sobre el discurso (espacio retórico).

El escrito, de acuerdo con este modelo, será el resultado de la resolución del problema de la tensión entre los dos espacios, para lo cual será necesario, naturalmente, adoptar unas formas determinadas. El proceso de «decir los conocimientos» queda integrado como un elemento dentro de un modelo explicativo que da cuenta de un proceso de escritura que lleva, según los autores, a la elaboración del conocimiento. En la escritura el receptor no puede contribuir a la elaboración del contenido, no puede haber negociación del significado; no hay realmente colaboración si no es muy diferida. El receptor es un elemento más de la situación retórica, junto con el tema y la intención. 


\section{COMPLEJIDAD DE LA TAREA DE REDACCION: LA SITUACION DE SOBRECARGA COGNITIVA}

El análisis del proceso de redacción pone de manifiesto la complejidad de la tarea que, a menudo, conlleva lo que se ha llamado una situación de sobrecarga cognitiva (Collins y Gestetner, 1980, Flower y Hayes, 1980; De Beaugrande, 1982; Scardamalia, Bereiter y Goelman, 1982). Cuando se escribe es necesario activar en la memoria a largo plazo los contenidos semánticos; darles, en primer lugar, una organización jerárquica y transcribirlos luego en una organización lingüística lineal, lo cual exige tener en cuenta aspectos de la estructura textual, gramaticales, léxicos, ortográficos, etc. Al mismo tiempo hay que tener en la mente los condicionantes del contexto de escritura como son la intención y la audiencia. Así pues, se llevan a cabo simultáneamente tareas globales y locales. Es decir, el proceso de redacción no es una secuencia lineal de estadios sino que, por el contrario, exige responder a la vez a múltiples exigencias, cada una de las cuales afecta al producto final. Así pues, la madurez en la escritura implica un gran número de habilidades a diferente nivel de procesamiento. El problema del escritor es cómo mantener «todas estas pelotas en el aire» dados los límites de la memoria a corto plazo (Flower y Hayes, 1980).

El escritor adulto y experto puede llevar a término con relativa facilidad esta tarea porque ha desarrollado una serie de estrategias que le permiten «jugar" con las diversas exigencias que impone la redacción, entre las cuales, como veremos, la automatización y coordinación de algunas habilidades, lo cual permite una más eficaz distribución del tiempo (Bereiter, 1980). En cambio los aprendices, que no han desarrollado estrategias adecuadas, centran su atención en los niveles locales (ejecución gráfica de las letras, ortografía, selección léxica, etc.) y no pueden atender a los niveles superiores de procesamiento del texto. Scardamalia (citado en Bereiter, 1980) estudió la coordinación entre esquemas de contenidos en escritos expositivos de niños de 10 a 14 años y observó que niños que eran capaces de manejar simultáneamente de tres a cinco esquemas de contenido en la producción oral, tendían a manejar sólo de uno a tres en el escrito. Esto sugiere que están tan centrados en la resolución de problemas de nivel superficial que tienen poca capacidad de atención sobrante para aspectos globales referidos, por ejemplo, al significado. La mayor o menor habilidad de los niños depende, en parte, de lo que pueden mantener en la mente mientras están escribiendo (Scardamalia, Bereiter y Goelman, 1982).

\section{ESTRATEGIAS PARA RESOLVER EL PROBLEMA DE SOBRECARGA COGNITIVA}

A partir del análisis del proceso de redacción muchos autores han especificado algunas estrategias que los escritores utilizan para resolver el problema de sobrecarga cognitiva. En teoría, la manera más sencilla de resolver el problema de las exigencias excesivas de la redacción consistiría en dividir la tarea en estadios temporalmente independientes, como sugieren los modelos de etapas. De hecho, aunque muchos autores insisten en la no linealidad del proceso y en su recursividad, presentan alguna de estas estra- 
tegias estrechamente relacionadas con las diferentes etapas del proceso, como recursos para resolver los problemas que cada uno de los subprocesos presenta. Este es el caso, por ejemplo, de las propuestas de Collins y Gestether (1980), de Flower (1981) y de Murray (1984). Otros autores se centran en alguno de los subprocesos y proponen estrategias específicas orientadas a la resolución de los problemas que plantea. Por ejemplo $\mathrm{Be}-$ reiter (1980) propone estrategias para resolver los problemas de la revisión para los que están aprendiendo a redactar.

Parece, sin embargo, interesante comentar las estrategias más generales que utilizan los escritores para abordar las dificultades que presenta el texto. Flower y Hayes (1980), en el análisis de los protocolos de pensamiento oralizado, observan que las más utilizadas por los escritores para reducir la presión de los distintos requerimientos simultáneos son:

a) Dejar de lado uno de los requerimientos; por ejemplo, escogiendo ignorar la audiencia, o la convención que exige coherencia entre párrafos, etc.

b) - Dividir el problema en subprobemas semi-independientes. Hay que tener en cuenta, sin embargo, que la independencia completa entre subprocesos no es posible y por tanto los escritores enfocan selectivamente la atención en un aspecto o en otro, que pasan a un primer término, pero relacionados siempre con los demás aspectos del texto.

c) Establecer prioridades $y$ "darse por satisfecho" en otros aspectos. En general, el escritor escoge los objetivos que quiere conseguir y el nivel que desea alcanzar; por ejemplo, conseguir un tono amistoso, aunque sea en detrimento de la coherencia entre las partes. Cuando da prioridad a alguna de las exigencias, el escritor decide «darse por satisfecho» en otras. A menudo esta estrategia se combina con la de dividir el problema cuando se decide «darse por satisfecho» en algún aspecto en la primera redacción para mejorarlo posteriormente en la revisión.

d) Convertir en rutina o procedimiento bien aprendido alguna de las operaciones implicadas; es decir, automatizar algunas operaciones de manera que no ocupen más que un pequeño espacio mental del escritor para liberar, de esta forma, una capacidad mayor que asegure la gestión a niveles superiores del procesamiento.

e) Hacer planes. Esta es una estrategia a la cual los autores atribuyen un alto grado de efectividad en la mejora de la redacción porque, además de reducir los elementos que cargan la memoria a corto plazo, permite integrar las exigencias múltiples de la composición y muestra cómo ir resolviendo los problemas. Los planes son, en cierto sentido, una defensa del escritor contra la complejidad inherente en la redacción. Los más útiles son los de naturaleza flexible, que establecen prioridades y definen los objetivos generales del escrito.

Flower y Hayes (1980) distiguen tres tipos de planes: 1) planes para hacer, orientados a definir el acto de habla, a responder al problema retórico. Estos planes generan dos clases de subplanes: 2) planes para decir, constituidos por una versión simplificada o abstracta de la información que se quiere desarrollar, y 3 ) planes para componer, que guían el proceso de composición y que están orientados a generar conocimientos o a decidir entre procedimientos alternativos a la hora de escribir el texto. Los buenos 
escritores se distinguen por su capacidad de formular planes para hacer y de revisarlos y reformularlos, si es necesario, durante el proceso de redacción. Los escritores deficientes o los aprendices, en cambio, se limitan a la formulación de planes para decir, que son, por otra parte, los únicos que se acostumbran a exigir en la escuela.

La tesis de Flower y Hayes es que una manera de mejorar la redacción consiste en mejorar el proceso de planificación, poniendo énfasis en los planes para hacer, estableciendo, por ejemplo, con claridad la intención y los receptores del escrito.

\section{ENFOQUE SELECTIVO O FOCALIZACION}

La complejidad de la actividad de redacción tiene como consecuencia, como decíamos, la dificultad de tener en la mente a la vez todos los aspectos que la configuran (desde los objetivos globales a las tareas de selección léxica o a la resolución de los problemas ortográficos). Como se desprende de los diversos modelos conginitivos, especialmente del De Beaugrande (1984) es imposible separar cada uno de los subprocesos respecto del proceso global. Por ejemplo, la capacidad de encontrar la palabra adecuada no puede ser ejercitada al margen del contexto comunicativo y lingüístico de los cuales esta palabra tendrá que formar parte.

Flower y Hayes, al hablar de la estrategia de dividir el problema en subproblemas semi-independientes, apuntan que lo que hacen los escritores es enfocar selectivamente la atención en uno u otro aspecto del escrito. De Beaugrande (1982) al hablar de los aprendices dice que para ellos «el éxito depende principalmente de ser capaces de eleborar sus propios problemas hasta que sean claros y tratables de acuerdo con la técnica de resolución de problemas, descomponiéndolos en subproblemas». Con esta idea desarrolló programas de enseñanza en los cuales el principio fundamental era justamente enfocar selectivamente alguno de los subproblemas dejando en segundo plano otras consideraciones hasta que los aprendices ganaban confianza en la cuestión seleccionada. La idea subyacente es que el desarrollo de las capacidades aisladas no conduce necesariamente a la mejora de la capacidad de redacción para la cual todas las habilidades han de estar interrelacionadas y guiadas por objetivos globales. Pero al mismo tiempo el aprendizaje de la redacción no sería posible si no se pudiera analizar el proceso global en subprocesos y no se pudiera determinar las habilidades implicadas para poderlas ejercitar selectivamente. La enseñanza de la redacción puede plantearse como un proceso dialéctico entre actividades globales y actividades locales integradas en proyectos. La programación puede poner el acento en alguno de los subprocesos o habilidades implicados que pasarán a ocupar la atención preferente de profesores y alumnos. Los demás aspectos o están ya automatizados o no se les dará importancia por el momento, o bien el profesor y la situación escolar los facilitarán para que no acaparen la atención del alumno.

\section{CONCLUSION: ALGUNAS IMPLICACIONES PARA LA ENSEÑANZA}

Los modelos psicológicos del proceso de redacción no son modelos de enseñanza. Sin embargo, de estas investigaciones podemos inferir algunas 
ideas que sirvan de base a una reorientación de la enseñanza de la redacción en la escuela.

La primera de ellas parte de la simple constatación de que escribir es un proceso que se desarrolla en el tiempo a través del cual el escritor realiza diversas operaciones, no lineales, sino recursivas y que las habilidades requeridas para llevarlo a término son muy diversas. La orientación de la enseñanza de la redacción al proceso, y no sólo al control del producto, parece necesaria para que el profesor pueda intervenir en el desarrollo de las operaciones implicadas y en ofrecer posibilidades al alumno de ejercitar-se en las diversas habilidades requeridas. Desde el punto de vista de la organización, la enseñanza de la redacción que quiera incidir en el proceso hace imprescindible un espacio en el horario escolar que permita la elaboración del escrito en colaboración entre los alumnos y en interacción con el profesor.

Los modelos cognitivos han puesto de relieve la globalidad del proceso de escritura. A pesar de que las operaciones que se realizan y los conocimientos y habilidades que se requieren son múltiples, todos interactúan durante el proceso de producción, aunque hay en cada momento una operación dominante. Desde este punto de vista, la enseñanza de la redacción tendría que partir de la propuesta de actividades globales. La programación, en lugar de orientarse a la ejercitación de habilidades y a la adquisición de conocimientos lingüisticos de forma aislada e independiente, podría orientarse a enfocar selectivamente la atención en uno u otro de los aspectos implicados. Este enfoque tendría como consecuencia la necesidad de revisar la enseñanza de la escritura que, o bien se basa en la producción intuitiva ỳ espontánea, que no se puede enseñar, o bien en la enseñanza de conocimientos lingüísticos sistemáticos relacionados únicamente con los aspectos más superficiales del texto y que, en general, aprenden sin relación con las situaciones de escritura real.

Para que escribir pueda llegar a ser un instrumento de elaboración de los conocimientos es necesario que el alumno experimente la tensión entre algo que quiere decir y el lenguaje y la situación comunicativa que tienen sus imposiciones. Para que esta situación se dé, el alumno tiene que tener realmente algo que decir y el contexto tiene que imponer realmente sus exigencias. De ahí la necesidad de basar la enseñanza de la redacción en situaciones reales de escritura.

Para el aprendizaje de la redacción no es suficiente un entorno agradable que estimule y dé soporte a los alumnos. Es necésario que éstos experimenten las dificultades inherentes al proceso. No todas las actividades escolares de redacción llevan al aprendizaje progresivo de esta actividad. El alumno puede escribir mucho y en cambio no aprender estrategias adecuadas para que la escritura se convierta en un instrumento de transformación de conocimientos y de elaboración del pensamiento. Cada actividad de escritura tendría que constituir un problema de tensión entre lo que se quiere decir y la situación de comunicación, que habría que establecer previamente (escribir para unos receptores identificables, con una intención determinada). De esta forma podría evitarse que el único problema que los alumnos tuvieran que resolver fuera el de cumplir con una tarea escolar.

Para que la complejidad del proceso no bloquee la escritura y obligue a los estudiantes a adoptar estrategias inadecuadas es conveniente propor- 
cionarles ayudas que les faciliten el proceso y les permitan centrar su atención en la operación que interesa. El trabajo en grupo, la interacción con el maestro, el uso de cuestionarios, etc., pueden contribuir a que el alumno lleve a término una actividad compleja que no podría realizar solo. La enseñanza de estrategias de planificación y revisión parece especialmente conveniente por cuanto exigen el concurso de capacidades metacognitivas imprescindibles para el control consciente de la actividad de redacción.

La adquisición de la competencia escrita tiene que ser un objetivo no sólo del profesor sino también de los estudiantes. Para ello es necesario que puedan conocer los objetivos de las actividades que llevan a término. Lo cual significa que, aparte de la necesidad de que las tareas constituyan situaciones reales de escritura, será necesario también que se programen como situaciones en que el alumno tenga que aprender algo, resolviendo, como decíamos, el problema que en cada caso se plantee.

\section{Referencias}

APPLEBEE, A. N. (1982). "Writing and learning in school setting». En M. NYSTRAND (Ed.). What writers know. Nueva York: Accademic Press, pp. 365-381.

Beaugrande, R. DE (1982). "Psychology and Composition: Past, Present and Future». En Nystrand, M. (Ed.). What writers Know. Nueva York: Academic Press, pp. 211-267.

- (1984). Text Production. Towards a Science of Composition Norwood, N. J.: Ablex.

BEREITER, C. (1980). «Development in Writing». En GREGG, L. W., y STEINBERG, E. R. (Ed.). Cognitive Processes in Writing. Hillsdale, N. J.: Erlbaum, pp. 73-93.

BerEITER, C., y SCARdamalia, M. (1983). "Does learning to write have to be so difficult?". En Freedman, A., Pringle, I. y Yalden, J. (Eds.). Learning to Write. First Language/ Second Language. Nueva York: Longman, pp. 12-19.

- (1987). The Psychology of Written Composition. Londres: Erlbaum.

BRIDWELL, L. (1980). "Revising Strategies in Twelfth Grade Students" Transactional Writing". Research in the Teaching of English, 14. pp. 197-222.

Collins, A. y GENTNER, D. (1980). «A Framework for a Cognitive Theory of Writing». En Gregg, L. W. y Steinberg, E. R. (Eds.). Cognitive Processes in Writing. Hillsdale, N. J.: Erlbaum, pp. 51-72.

EMIG, J. (1971). The composing processes of twelfth graders. Champaign, I. L.: National Council of Teachers of English.

FLOWER, L. (1981). Problem-solving strategies for writing. Nueva York. Harcourt Brace Jovanovich.

Flower, L. y Hayes, J. R. (1980). "The Dynamic of Composing». Making Plans and Juggling Constraints. En GREGG, L. W. y STEINBERG, E. R. (Eds.). Cognitive Processes in Writing. Hillsdale, N. J.: Erlbaum, pp. 31-50.

- (1981). "A Cognitive Process Theory of Writing». College Composition and Comunication, 32 (4), pp. 365-387.

Gregg, L. W. y Steinberg, E. R. (Eds.). (1980). Cognitive Processes in. Writing. Hillsdale, N. J.: Erlbaum.

HAYES, J. R. Y FlOWER, L. (1980). «Identifying the Organisation of Writing Processes». En GregG, L. W. y STEINBerg, E. R. (Eds.). Cognitive Processes in Writing. Hillsdale, N. J.: Erlbaum, pp. 3-30.

- (1981). «Writing as a Problem Solving». Visible-Language, 14, 4, pp. 388-399.

MarTlew, M. (Eds.) (1983). The Psychology of Written Language: A Developmental Approach. Chichester: John Wiley and Sons.

MATSUHASHI, A. (1982). «Explorations on the Real-Time of Written Discourse». En Nystrand, M. (Ed.). What Writers Know. Nueva York: Academic Press, pp. 269-290.

Murray, D. (1984). Write to learn. Nueva York: Holt, Rinehart and Wisnton.

Nystrand, M. (Ed). (1982). What writers know. Nueva York: Academic Press.

PERERA, K. (1984). Chidren's Writing and Reading Analysing Classroom Language. Londres: Blackwell.

RohmAN, D. G. y WLECKE, A. O. (1964). Pre-writing. The construction and application of models for concept formation in writing. Office of Education. Cooperative Research Project, 2.174 .

Scardamalia, M. y Bereiter, C. (1985). «Development of Dialectical processes in Compo- 
sing». En OlsON, R. D., TORRANCE, N. y HildyARD, A. (Ed.). Literacy Language, and Learning. The Nature and Consequences of reading and writing. Londres: Cambridge University Press, pp. 307-329.

Scardamalia, M., Bereiter, C. y Goelman, H. (1982). «The Role of Production Factors in Writing Abilitym. En NySTRAND, M. (Ed.). What Writers Know. Nueva York: Academic Press, pp. 173-210.

WELLS, G. (1986). The Meaning: Children Learning Language and Using Language to Learn. Portsmouth, N. H. Heinemann (Trad. cast.: A prender a leer y escribir. Cuadernos de Pedagogia, Barcelona: Laia, 1988).

\section{Extended Summary}

Cognitive models of writing processes are having a great influence on language instruction, in particular, with respect to the introduction of literacy. These models differ from the so called «stage models» in that their aim is to explain the writer's internal processes when writing.

In this paper, some of the contributions made on this issue are analyzed, specifically the cognitive models proposed by Hayes and Flower (1980), De Beaugrande (1984), and Bereiter and Scardamalia (1987).

Hayes and Flower's model stresses the complexity both of the cognitive processes involved in the writing activity and of the elements that affect this process, i.e., the writer's knowledge, and task context. They see the writing task as a problem that must be solved on the basis of the demands made by the communicative situation. From the task representation, the writer builds a network of goals. These will guide him/her in the production process. This model stresses the task's control mechanisms guided by the writer's overall goals.

According to Beaugrande, one of the main characteristics of the writing process is its recursivity. This author analyses in depth the general criteria that should guide any model of this process. He emphasizes the interaction between the different stages of the writing process, which he also considers are initially based on the establishment of general goals, and later in confronting decisions at a specific level. Each part of the writing process is dominated by a specific phase, but there is constant interaction between the different phases. This is not necessarily in one direction, there are constant changes between the different phases.

Bereiter and Scardamalia start from the notion, shared by other authors interested in the cognitive processes involved in composition, that writing may act as a tool for the elaboration of knowledge. However, they observe that this is not always the case. Frequently, learners used strategies which are inadequate. Hence, they propose two models, the «knowledge telling" model, which describes the process involved in writing down ideas as they are retrieved from memory, and the "knowledge tranforming" model, in which the writing process is seen as a task were meanings are represented through a process of tenseness between the content and the rhetorical situation. The difference between these two models does not lie on the written product, but on the cognitive processes involved. According to these authors, school education does not foster a model that allows for the elaboration of knowledge.

The complexity of the writing task is such that it may lead to situations 
of cognitive overloading. The use of the apropiate strategies allows expert writers to avoid or overcome this situation. Some of the strategies used by experts are: planning the content of the product and the process to follow, focusing on the relevant aspects of the composition, automating some operations, etc.

Some relevant issues for teachers are:

1. The importance of focusing instruction not only on the product of the writing activity but also on the writing process itself. This allows the teacher to intervene in the operations that learners undertake.

2. The need of considering the writing task as a whole, as a complex problem that must be solved and which involves taking decisions on the basis of preestablished goals, related both to the content and to the communicative situation.

3. Writing instruction should be programmed in advance, so that problems are dealt with selectively within the framework of the overall essay writing activities.

4. The need to teach adequate strategies to students and to provide them with ways of dealing with their writing problems. In this respect, the beneficial influence of teacher-student interaction during the writing process is underlined. 